\title{
Discussion on Tourism Logistics Based on the Separation and Combination of Tourists and Items Theory
}

\author{
Zhiyang Jin 1,2,3, Kunhao Dai ${ }^{3 *}$, Guohua Fu ${ }^{3,4}$, Yang $\mathrm{Li}^{3}$ \\ ${ }^{1}$ School of Automotive and Traffic Engineering, Jiangsu University, Zhenjiang, China \\ ${ }^{2}$ Mechanical and Electrical Engineering College, Hainan University, Haikou, China \\ ${ }^{3}$ Haina Policy and Industrial Research Institute of Low-Carbon Economy, Haikou, China \\ ${ }^{4}$ School of Economics and Management, Hainan University, Haikou, China \\ Email: *1129087420@qq.com
}

How to cite this paper: Jin, Z.Y., Dai, K.H., Fu, G.H. and Li, Y. (2017) Discussion on Tourism Logistics Based on the Separation and Combination of Tourists and Items Theory. American Journal of Industrial and Business Management, 7, 537-547. https://doi.org/10.4236/ajibm.2017.74039

Received: March 15, 2017

Accepted: April 27, 2017

Published: April 30, 2017

Copyright $\odot 2017$ by authors and Scientific Research Publishing Inc. This work is licensed under the Creative Commons Attribution International License (CC BY 4.0).

http://creativecommons.org/licenses/by/4.0/

\begin{abstract}
In order to understand the essence of tourism logistics activities, the author studies and summarizes the existing research results of tourism logistics at home and abroad, finding that there exist two kinds of logistics phenomena in tourism industry. Then, the author analyses in-depth the cross process between the two kinds of logistics phenomena and tourist flow from the perspective of time and space as well as identifies the key factors in the process of their separation and combination. Next, focusing on the two kinds of logistics phenomena, the author completely explains the process of the tourism logistics activities via the in-out transformation mechanism. Finally, the functions and objectives of the tourism logistics system are defined through the separation and combination of tourists and items theory in this paper, which provides instructive directions for future research.
\end{abstract}

\section{Keywords}

Tourism Logistics, Logistics Economy, The Separation and Combination of Tourists and Items Theory, In-Out Transformation Mechanism

\section{Concept and Connotation of Tourism Logistics}

With the refinement and marginalization of social division of labor, domestic and foreign scholars gradually realize the importance of logistics activities in tourism activities and the demand for logistics in tourism industry, therefore, a highly cross noun- "tourism logistics" is put forward. Although there isn't a unified understanding about the concept of tourism logistics currently, its defi- 
nitions worthy for reference have been come up at home and abroad.

Kochadze $\mathrm{T}$ finds that the logistics is one of the main sources of profits for service providers in tourism industry. Through constantly optimizing the logistics management process and correctly planning, managing, manipulating information and actions, profits can be gained, customers' tourism process can be adjusted as well as the supporting, promoting and restrictive role played by logistics in tourism activities can be identified [1]. K Segestlija Z believes that the logistics system in tourist destinations includes five modules: order fulfillment, inventory management, warehousing and dispatching, packaging and reorganization and vehicle [2]. Mrnjavac E thinks that tourism logistics refers to the coordination and optimization of substances, personnel, information, energy, waste, knowledge and capital at the lowest possible cost from the perspective of time and space so as to provide high quality tourism service [3]. Ivanovic $\mathrm{Z} \mathrm{em}$ phasizes the importance of researching tourist destinations as a whole and comes up with the logistics system of tourist destinations based on systematic science. The lower levels of the logistics system are operational function system, information function system and management function system, which can be further decomposed into functional subsystems, namely, critical business processes [4]. Muhcina S argues that internal logistics activities in the tourism supply chain refer to the process from raw material suppliers to the final consumers, involving procurement, operations, and some other parts which are similar to material transfer and supply chains and are formed by cooperations among different numbers of participants [5]. Piboonrungroj P, taking Thailand's cultural and creative tourism as an example, proposes five elements of tourism logistics management, including infrastructure, information, intelligence, identification and innovation and further points out that logistics management is essential and significant to support creative tourism activities, reduce costs and elevate tourists' satisfaction [6]. Bosun P holds the view that the rapid development of the Internet has changed the traditional logistics process, involving changes in logistics functions, which requires tourism enterprises to adapt to electronic logistics [7].

Many domestic scholars analyze the connation of tourism logistics from broad and narrow senses, roughly forming the following three categories of views. The first one analyses the connation of tourism logistics from the perspective of tourism flow. Based on Pearce [8] and McIntosh [9]'s research of tourism flow, Tang Shuntie and GuoLaixi [10] propose the "tourism logistics" for the first time to expand the connotation of tourism flow through their analysis of modern tourism flow system. They think that tourist flow is accompanied by tourism logistics, which means that due to the implementation of tourism activities, material flow is generated between tourist origins and tourist destinations. The second one studies the connation of tourism logistics from the perspective of interaction between tourism industry and logistics industry. Li Xiaodong [11] puts forward that tourism logistics mainly refers to a series of logistics activities of tourists in the process of tourism, including tourism transit, tourism resource 
supply and the adoption of related logistics technology to manage tourism vehicles and tourists. The last point about the connation of tourism logistics is established via using the method of comparative analysis. By comparing the similarities and differences between tourism and logistics, tourism industry and logistics industry, Ji Liangxin [12] thinks that tourism and logistics activities are customer-oriented and that the essence of tourism logistics is various logistics phenomena and relationships, specifically, the material flow caused by tourists in tourism activities from tourist origins to tourist destinations.

Considering the above three kinds of understandings of tourism logistics, the following two conclusions can be drawn. Firstly, the tourism logistics aims to provide better service for tourists and is a kind of logistics activities which are accompanied by the tourist flow. Narrowly, it refers to flow process of all tangible materials in tourism industry; broadly, it refers to the total of all phenomena and relationships that are associated with tourism activities and material flow. The second conclusion is about the value of tourism logistics, which is reflected in enhancing the tourism experience of tourists, reducing the operation cost and improving the overall operational efficiency of tourism industry etc.

Although there exist different ideas of tourism logistics, it is inseparable from three tourism factors in tourism activities, namely, tourists, tourist destinations, tourism media. While tourists and tourism media play the leading roles in tourist activities, tourists and tourist destinations are the creators of tourism logistics. The three tourism factors define the border of economic activities, which includes tourists conduct tourism activities in pursuit of personal values and spiritual pleasure; tourism media carries out the activities of procurement, supply and sale etc to meet consumers' demands. But they focus on describing the dialectical relationship among themselves and don't mention the process of tourism logistics. So, in order to explain how tourism logistics is generated, the author studies the process of tourism logistics on the foundation of the three tourism factors.

\section{Two Kinds of Logistics Phenomena in Tourism Industry}

The three tourism factors define the border of economic activities in tourism industry, namely, on the basis of certain tourism resources, all the economic behaviors involved in the tourists' tourism behaviors are based on tourists' pursuit of personal values and spiritual pleasure. At the same time, tourism service providers carry out the appropriate economic preparatory work to support and meet the travel needs of tourists. As shown in Figure 1, tourism activities are the total of all the relationships and phenomena that relate to the tourism behaviours and can act on the three tourism factors, including the external activities triggered by the tourism behaviors of tourists and the internal activities that support the construction, operation and development of tourism service providers. Besides, the external activities include the economic and cultural exchanges between tourists and tourists; the internal activities include the business activities and information communication between tourists and tourism enterprises, tourism enterprises and tourism enterprises. The internal activities are 


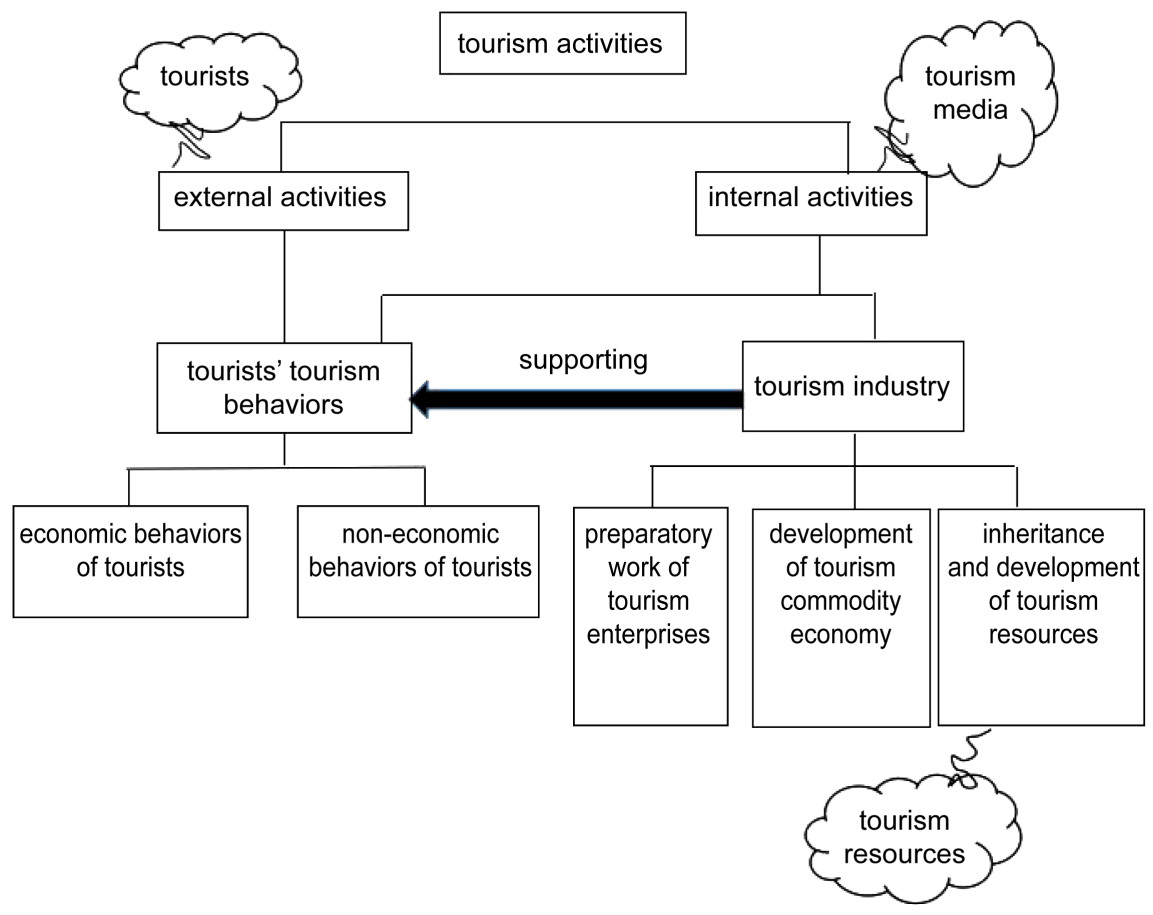

Figure 1. Origin chart of tourism activities.

performed on the basis of the external activities, and thus become an important part of tourism activities. Whether it is the tourists' tourism activities, or economic preparations conducted by travel service providers, they always concentrate on and are fulfilled around "six elements"- "food, housing, transportation, travel, shopping and entertainment."

The three tourism factors determine the main bodies of tourism activities with economic nature, which also cover tourists and travel service providers. On the one hand, tourists will carry objects and buy commodities with certain volume and weight in the initial departure and in the process of travel, including daily necessities, necessary equipments and specialties and so on. With the spatial displacement of the tourists, these items carry out the same spatial movement under the same time series. On the other hand, tourism service providers perform economic activities similar to traditional manufacturing, like production, processing, procurement and storage etc. to satisfy the current and future tourist needs for "six elements". During these economic activities, various types of logistics activities are involved. According to the essence of logistics, all flows of tangible materials are a kind of "logistics" phenomenon, so the logistics phenomena in the tourism industry include material flow generated by tourist flow and logistics activities generated by the economic preparatory work of tourism service providers.

In the traditional manufacturing fields, the important function of logistics research lies in the realization of the operational optimization of raw materials from mining, producing, processing, manufacturing to selling and recycling, which means that these economic activities are done with higher efficiency and lower cost. However, in addition to the economic logistics activities in tourism 
industry are similar to the manufacturing logistics; the existing material flow accompanied by tourists is also an objective fact. As the items carried by tourists on the way are subject to the objective conditions, so the items tourists can carry have the upper limit. These objects, on the one hand, make it difficult for tourists to buy more goods to meet the individual's economic pursuit. On the other hand, carrying too many items will become the burden of tourists, which can affect the freedom of travel, and be not conducive to tourists' spiritual enjoyment and travel experience. Objects that the tourists think have certain value and function in the journey and that make spatial movement with the spatial displacement of the tourists are called "in-transit items" in this paper, including tourists personal objects and commodities bought halfway.

Through the observation of tourists' travel process, it is possible to directly discover that when tourists carry personal objects travel to the locations of travel service providers and conduct economic transactions, the commodities (gifts, specialties or daily consumables etc.) merger with tourists. Although they occur in different spatial domains, but get together in the same time-space domain. As shown in Figure 2, when in the range of time domain $\mathrm{X}(1)$, the flow of "intransit items" and the tourist flow are in the same space domain $Y(2)$, and the tourism commodity flow is in the space domain $\mathrm{Y}(1)$. When in the range of the time domain X(2), the flow of "in-transit items", the tourist flow and the tourism commodity flow gather in the range of the time domain $\mathrm{X}(2)$ and the space domain $\mathrm{Y}(1)$. In the figure, the process $\alpha$ indicates that the tourists and travel service providers reach a transaction, tourism commodities are transformed into "in-transit items" of tourists, or consumed by tourists.

In order to distinguish the two kinds of logistics phenomena, this paper calls tourism commodities needed, provided and sold by tourism service providers as A items and calls tourists' belongs whose ownerships are possessed by tourists

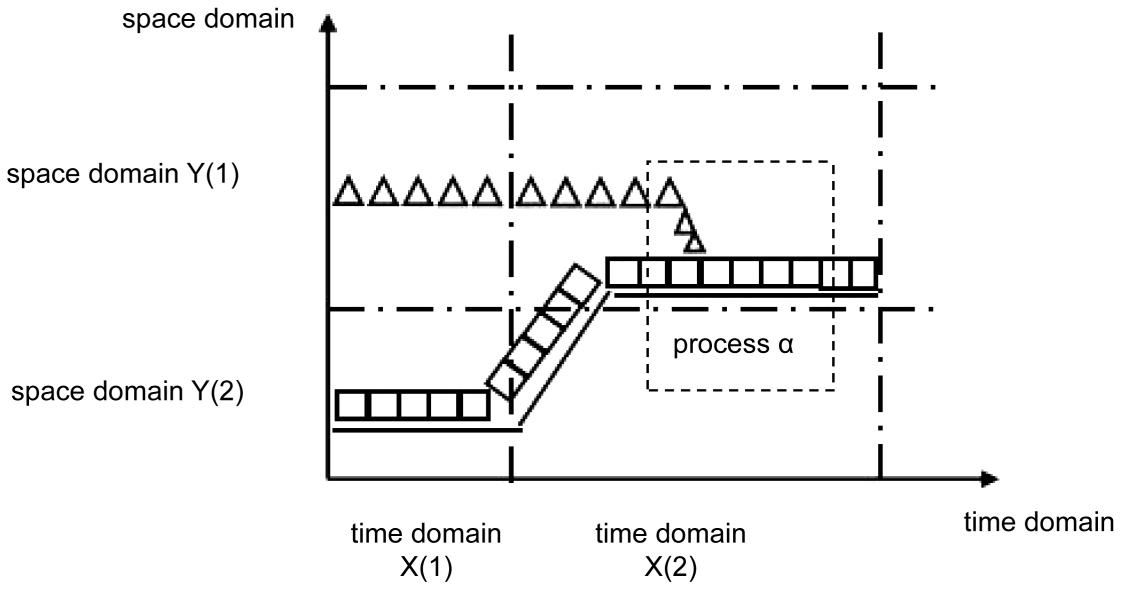

" $\Delta$ " tourism commodities; " $\boldsymbol{\Delta} \boldsymbol{\Delta} \boldsymbol{\Delta} \boldsymbol{\Delta} \boldsymbol{\Delta}$ " tourism commodity flow; " $\boldsymbol{\square}$ " in-transit items;

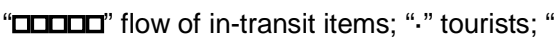
" tourist flow;

"- - - space-time segmentation line

Figure 2. Behavioral characteristics of tourist flow, flow of "in-transit items" and tourism commodity flow in space-time domain. 
as B items (Table 1). The flow process caused by space displacement of A items and $\mathrm{B}$ items is the above-mentioned two kind of logistics phenomena, the process $\alpha$ represents the transformation process of A items to B items.

Based on the behavioral characteristics of the three flows (tourist flow, B item flow, A item flow), it can be found that the tourism commodity flow tends to be merged with the tourist flow and the flow of "in-transit items". The reason of such tendency can be concluded from Figure 1. Tourists have great consumption needs for the "six elements" - "food, housing, transportation, travel, shopping and entertainment," which makes the process $\alpha$ shown in Figure 2 is repeated constantly.

Based on the above analysis, the A item flow is one of the basic activities of tourism development and is an important guarantee for tourists to carry out the tourism activities. Logistics operation of A items, one of the two kinds of logistics phenomena in tourism industry, is a necessary component of tourism logistics. At the same time, as for another kind of logistics phenomenon-B item flow, how to effectively lighten the burden it causes to tourists and enhance the tourism experience of tourists are important issues directly faced by tourism logistics.

\section{Separation of B Items from Tourists}

The B items constantly change in time and place along with the travel process of tourists, which causes burden to tourists in journey. On the one hand, some of the $\mathrm{B}$ items are the necessary stuff in the whole travel process to meet the basic needs and daily habits of tourists, so it is a completely infeasible approach to unilaterally cut or even restrict things carried by tourists; on the other hand, as we know, B items are the ones that tourists buy and consume when travelling around, but due to the fact that there is upper limit of a single person's carrying capacity and the actual carrying capacity of a single person can not be reduced, tourists' purchasing power can't be fully excavated. Therefore, whether from the perspective of the tourists' tourism experience, or from the perspective of the

Table 1. Classification of items in tourism industry.

\begin{tabular}{cll}
\hline General Category & Main Category & \multicolumn{1}{c}{ Subcategory } \\
\hline Food & $\begin{array}{l}\text { Vegetables, meat, eggs, flour, soy products, } \\
\text { seafood, spices etc. }\end{array}$ \\
A items & $\begin{array}{l}\text { Toothbrush, toothpaste, comb, shampoo, } \\
\text { shower gel etc. }\end{array}$ \\
Shopping & $\begin{array}{l}\text { Fruits, art and crafts, coconut processed food, } \\
\text { coffee, dried sea products, tea, wine, etc. }\end{array}$ \\
Personal objects & $\begin{array}{l}\text { Travel bags, clothing, shoes, electronics, digital } \\
\text { products, cosmetics, books, etc. }\end{array}$ \\
B Items & $\begin{array}{l}\text { Off-road bikes, riding equipments, surfboards, } \\
\text { diving equipments, fishing equipments, golf } \\
\text { clubs, adventure equipments, etc. }\end{array}$ \\
\hline
\end{tabular}


economic development of the tourism industry, it is necessary to solve the problems caused by the burden of $B$ items to tourists.

The key to solving the problem of B items is to find an effective way to separate the tourist flow from the $B$ item flow based on the trend of the combination of the A item flow, the B item flow and the tourist flow. As shown in Figure 3, when in the range of the time domain $\mathrm{X}(1)$, the $\mathrm{B}$ item flow is in the space domain $\mathrm{Y}(2)$ together with the tourist flow. When in the range of the time domain $\mathrm{X}(2)$, the $\mathrm{B}$ item flow is separated from the tourist flow, making the $\mathrm{B}$ item flow stay in the time domain $\mathrm{X}(2)$ and the space domain $\mathrm{Y}(1)$, while the tourist flow in the time domain $\mathrm{X}(2)$ and the space domain $\mathrm{Y}(2)$. In the figure, the process $\beta$ shows that the ownership of $\mathrm{B}$ items is transformed to tourists after certain process, but its time and spatial domain no longer keep consistent with the tourist flow, and items like this are called "out-of-transit items" in this paper.

When the B item flow is separated from the tourist flow, how to make it merger with the tourist flow in the space-time domain needed or prescribed by tourists is an important way for tourism logistics to solve the burden problems caused by $B$ items. As shown in Figure 4, when in the range of the time domain $\mathrm{X}(1)$, the $\mathrm{B}$ item flow is separated from the tourist flow, making the B item flow stay in the time domain $\mathrm{X}(1)$ and the space domain $\mathrm{Y}(1)$ while the tourist flow stay in the time domain $\mathrm{X}(1)$ and the space domain $\mathrm{Y}(2)$. When in the range of the time domain $\mathrm{X}(2)$, the $\mathrm{B}$ item flow is merged with the tourist flow in the time domain $\mathrm{X}(2)$ and the space domain $\mathrm{Y}(2)$. In the pictures, the process $\beta$ represents that the "B out-of-transit items" is transformed into "in-transit items" through certain process.

Through the separation and combination of B items and tourists, tourists' burden can be lighten according to their willingness in the actual process of tourism, so as to improve the tourists' travel freedom and explore their potential consumption capacity.

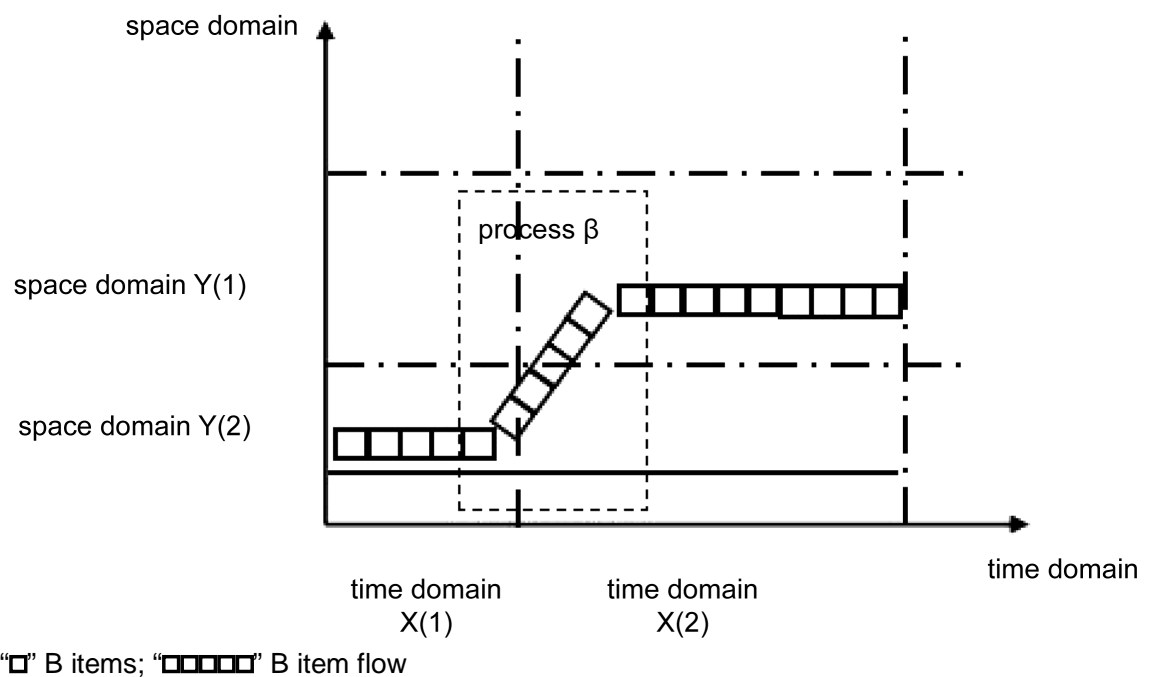

Figure 3. Schematic diagram of the separation of B item flow from tourist flow. 


\section{In-Out Transformation Mechanism}

Reviewing Figure 2 and based on the concepts of "in-transit items" and "outof-transit items" put forward in this paper, we can find: when we transform the A items that merger with the tourist flow into B items through the process $\alpha$, its transformation form and flow characteristics are nearly the same as those of the process when out-of-transit items are transformed into in-transit items. Therefore, in the logistics process of A items, we can regard A items as the "intended out-of-transit items" that will be transformed into B "in-transit items", which is a special condition of "out-of-transit items". As a result, we build an interpretation system of tourism logistics from the perspective of "in-transit items" and "out-of-transit items", as shown in Figure 5.

Here in the picture, in order to make a clear explanation, this paper calls the process $\beta$, the transformation from "in-transit items" to "out-of-transit items" as "forward transformation"; the process $\beta$, the transformation from "out-of-transit items" to "in-transit items" as "reverse transformation".

And a more concrete interpretation of "Tourism Logistics": tourism logistics refers to the total logistics relationships and phenomena, including supporting

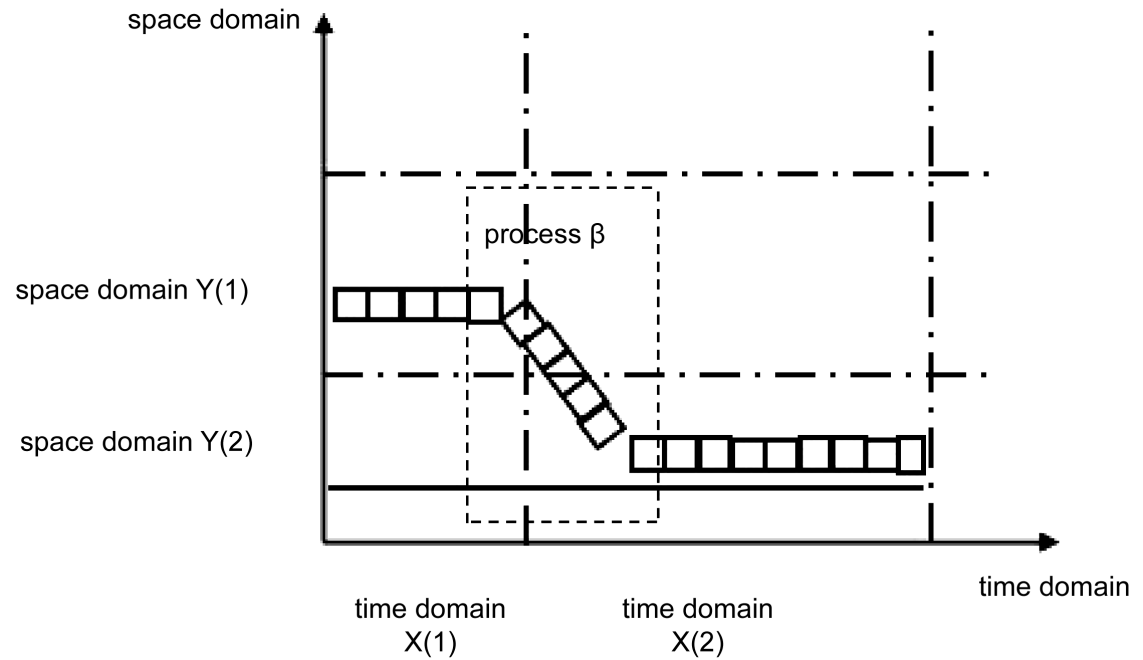

Figure 4. Schematic diagram of the combination of B item flow and tourist flow.

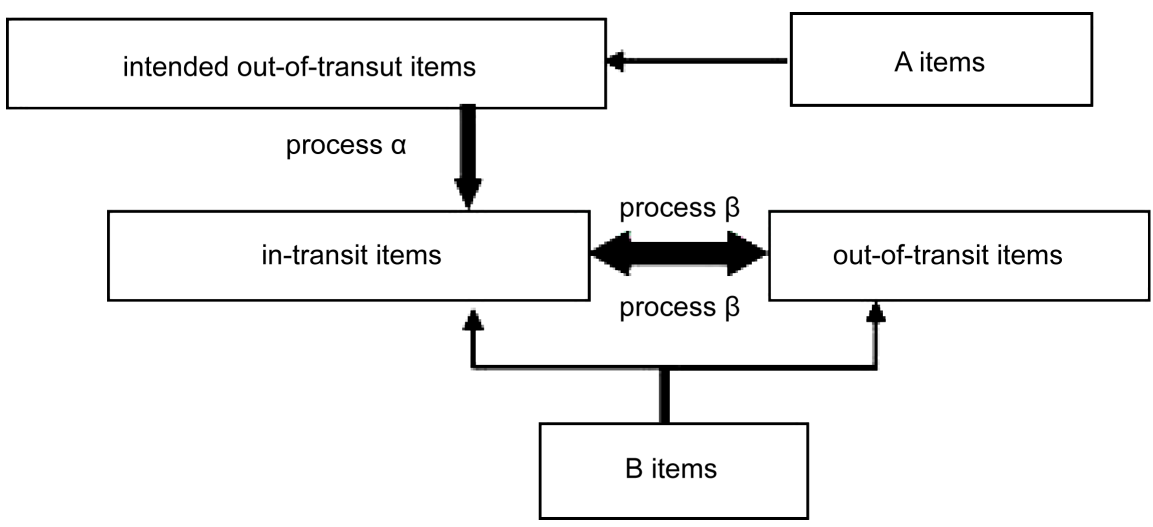

Figure 5. Tourism logistics interpretation mechanism of A items and B items. 
the realization of the transformation of the "in-transit items" from the "intended out-of-transit items" by the process $\alpha$ and satisfying the mutual transformation between "in-transit items" and "out-of-transit items". On this basis, from the perspective of the tourist flow path, the paper studies the logistics operation mechanism of the A items and B items in the tourism industry, that is, the operation mechanism of tourism logistics, as shown in Figure 6 and Figure 7.

\section{(1) In-out Transformation Process of B items}

The spatial location of tourists $\mathrm{D}(1)$ includes tourist origins and tourist destinations etc; accordingly, the spatial location of tourists $\mathrm{D}(2)$ includes tourist destinations, tourist origins or the next tourist destination etc.

From the tourist destination $\mathrm{D}(1)$ to the tourist destination $\mathrm{D}(2)$, tourists, with the help of the tourism logistics platform, achieve the transfer of the burden caused by B items in space and time. In Figure 6, when in the tourist origin, tourists pass $B$ items onto the tourism logistics entity to realize the forward transformation from in-transit items to out-of-transit items, which makes B items transform from in-transit state to out-of-transit storage state; and then tourists travel to the destination $\mathrm{D}(2)$ according to their plans, meanwhile the tourism logistics entity will transfer the out-of transit items according to the

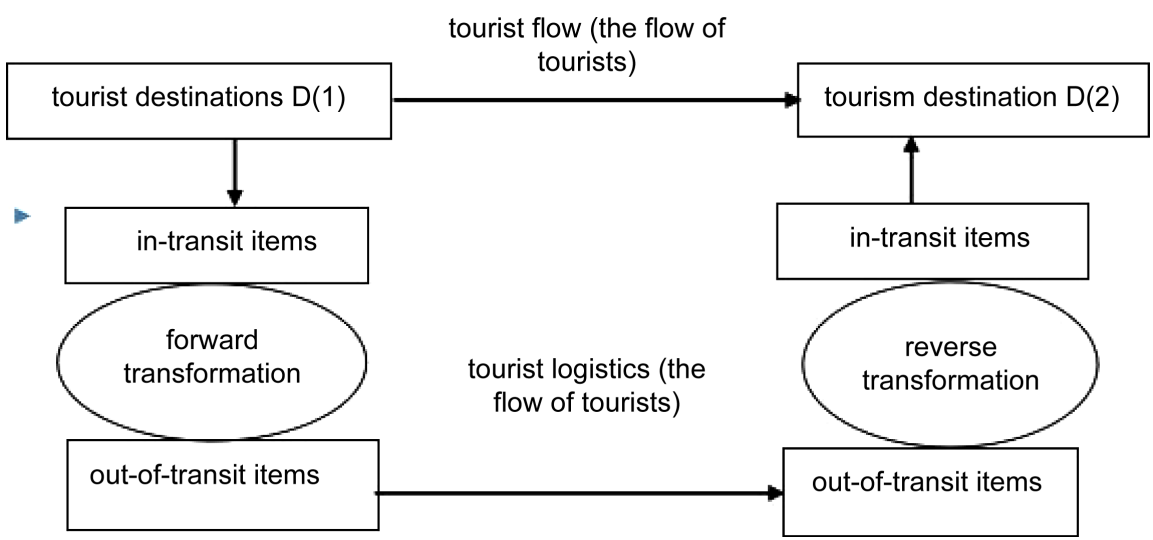

Tourist destinations $\mathrm{D}(1)$ - the spatial location of the tourist $\mathrm{D}(1)$

Tourism destination $\mathrm{D}(2)$ - the spatial location of the tourist $\mathrm{D}(2)$

Figure 6. In-out transformation mechanism between tourists and B items.

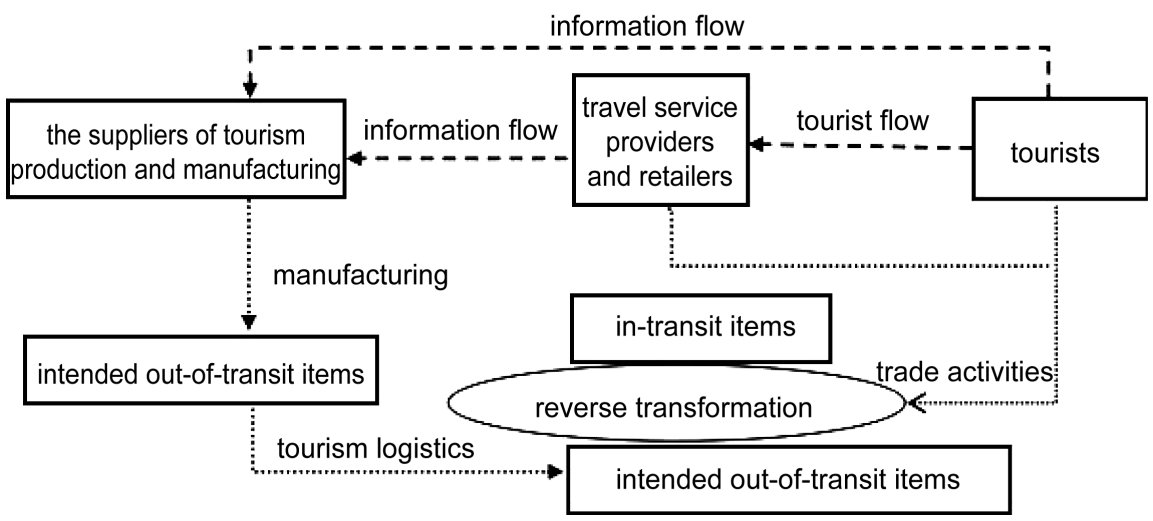

Figure 7. In-out transformation mechanism of A items. 
time and space requirements of tourists, which changes the B items from the out-of-transit storage state into the out-of-transit delivery state. After the completion of the transfer of the out-of-transit items from the tourist origin to the tourist destination of $\mathrm{D}(2)$, the tourism logistics entity in the tourism destination $\mathrm{D}(2)$ will transform the B items from being delivered to being stored and waiting for tourists in the remaining time to take their things, so as to complete the backward transformation from out-of-transit to in-transit.

(2) In-out Transformation Process of A items

Products provided by travel service providers in tourism industry, based on the six elements of tourists' demands, show the consumption characteristics of multi types, forms and functions. But A items generally refer to something with the economic nature and the entity shape, including consumables goods for travel, special tourism commodities, general goods etc.

In Figure 7, the tourism behaviors of large numbers of tourists happen orderly, which results in the formation of a large-scale tourist flow that can be shifted to the locations of the travel service providers with whom it can be directly linked with. In the above process, based on tourists' needs, the mechanism collects and processes valid information from the flow and then delivers the results to suppliers of A items.

Because the goods transfer takes certain time, the tourism product suppliers need to complete the process of evaluation and prediction in advance according to the information they get, so as to clearly guide and determine the working progress indexes of tourism enterprises in the next phase, and then finish the production and process of $\mathrm{A}$ items that are suitable for all kinds of tourist consumption, in other words, the intended out-of-transit items; on this basis and through the logistics distribution, A items are moved to the locations of the travel service providers in space who communicate directly with tourists, so as to allow the tourists to buy and consume A items in the locations of the tourist service providers, which refers to the reverse transformation of the in-transit items from the intended out-of-transit items.

\section{Conclusions}

Through the in-out transformation theory, this paper puts forward a new explanation for the tourism logistics of A and B Items, which, in essence, elaborates the specific process of when, where, and how "people"-tourists and "objects"A and B items, to separate and combine. Therefore, from the perspective of the overall tourism activities, tourism logistics is a series of logistics activities to make tourists and objects freely separate and merge with each other. Then it comes to the conclusion that the basic function of the logistics operation is to complete the forward and reverse transformation between the in-transit items and the out-of-transit items (including the intended out-of-transit items); the basic goal of the operation of tourism logistics is to realize the free separation and combination of tourists and items.

Based on the above theoretical analysis, how to complete the overall function 
of the tourism logistics and achieve the overall goal of tourism logistics as well as find space nodes suitable for the practice to support the free "in-out transformation" between A and B Items and tourists, have become the top priority of the current tourism logistics research. In addition, under the realistic background of the trend of horizontal expansion of the logistics industry and the high penetration of service industry in the logistics industry, to find a way of resource integration that combines the development of tourism industry and logistics industry, is also an important task for tourism logistics. On this basis, the establishment of a sound tourism logistics operation mechanism is the core content to perform the tourism logistics practice.

\section{References}

[1] Kochadze, T., Dangadze, I. and Zaqareishvili, V. (2013) The Role of Logistics in the Market for Transportation and Tourist Services. Machenes, Technologies, Materials, No. 4 .

[2] Segetlija, Z. and Lamza-Maronić, M. (2000) The Distribution System of Commercial Companies: Distribution, Logistics, and Informatics. Revised and Updated Edition, Faculty of Economics in Osijek.

[3] Mrnjavac, E. and Ivanovic, S. (2007) Logistics and Logistics Processes in a Tourism Destination. Tourism and Hospitality Management, 13, 531-546.

[4] Ivanovic, Z. and Baldigara, T. (2007) Logistics Processes in a Tourism Destination. Tourism and Hospitality Management, 13, 595-606.

[5] Muhcina, S. and Popovici, V. (2008) Logistics and Supply Chain Management in Tourism. The Amfiteatru Economic Journal, 10, 122-132.

[6] Piboonrungroj, P. and Sungkakorn, K. (2013) Tourism Logistics Management: A Case of Cultural Creative Tourism in Thailand. Proceedings of the 1 st World Conference on Hospitality, Tourism and Event Research and International Convention and Expo Summit 2013, Bangkok, 25-28 May 2013, 855-859.

[7] Bosun, P., Tenescu, A. and Dima, I.C. (2014) Informational Stocks and E-Logistics Management of a Tourism Company. International Letters of Social and Humanistic Sciences, 27, 75-85.

[8] Pearce, D.G. (1995) Tourism Today: A Geographical Analysis. Longman Scientific \& Technical, Harlow.

[9] McIntosh, R.W., Goeldner, C.R. and Ritchie, J.R.B. (1995) Pleasure Travel Motivation. In: Tourism: Principles, Practices, Philosophies, 7th Edition, 167-190.

[10] Tang, S.T. and Guo, L.X. (1998) Study on the Tourist Flow System. Tourism Tribune, 3, 38-41.

[11] Li, X. (2014) Layout Optimization of the Tourism Logistics Industry Chain in the Yangtze River Economic Belt. Logistics Technology, 33, 100-102.

[12] Ji, L. and Lin, D. (2009) Analysis of Tourism Logistics. China Collective Economy, 3,130-131. 
Submit or recommend next manuscript to SCIRP and we will provide best service for you:

Accepting pre-submission inquiries through Email, Facebook, LinkedIn, Twitter, etc. A wide selection of journals (inclusive of 9 subjects, more than 200 journals)

Providing 24-hour high-quality service

User-friendly online submission system

Fair and swift peer-review system

Efficient typesetting and proofreading procedure

Display of the result of downloads and visits, as well as the number of cited articles Maximum dissemination of your research work

Submit your manuscript at: http://papersubmission.scirp.org/

Or contact ajibm@scirp.org 